\title{
Objeto Virtual de Aprendizagem IncLuir: Recurso para a FormaÇão de Professores Visando à Inclusáo ${ }^{1}$ \\ Virtual LEARNing Object InCluir: a Resource for TEacher EdUCATION ADDRESSING INCLUSION
}

\author{
Cláudia A. BISOL ${ }^{2}$ \\ Carla Beatris VALENTINI ${ }^{3}$
}

\begin{abstract}
RESUMO: muito tem se discutido a respeito dos desafios e dificuldades da inclusão de estudantes com necessidades educacionais especiais, tal como vem sendo proposta pela política educacional brasileira a partir dos anos 1990. A literatura científica mostra que as lacunas referentes à formação inicial e continuada de professores constituem um dos grandes obstáculos para que a inclusão se torne realidade. O presente trabalho parte de uma discussấo a respeito da formação de professores para a inclusão e postula dois princípios como alicerces para essa formação: a ética da responsabilidade e a disponibilidade para o outro. Apresenta, em seguida, o objeto virtual de aprendizagem Incluir (OA Incluir), construído com o objetivo de criar um instrumento facilitador à formação de professores para a educação na perspectiva da inclusão. Dividido em quatro módulos (Limites, Diversidade, Docência e Surdez), este $\mathrm{OA}$ visa ultrapassar a transmissão de informação, propondo uma linha de reflexão que promova e mobilize novas práticas dentro de pressupostos interacionistas/construtivistas. As reflexôes desenvolvidas ao longo do OA são relatadas e brevemente discutidas. Uma análise quantitativa e qualitativa está em andamento e deverá sinalizar se o OA atinge o objetivo para o qual foi construído.
\end{abstract}

PALAVRAS-CHAVE: Educação Especial. Inclusão Educacional. Formação de Professores. Tecnologia Educacional.

ABSTRACT: Much has been discussed about the challenges and difficulties for inclusion of students with special educational needs, as proposed by the Brazilian educational policy since the 1990s. Scientific literature shows that gaps related to the initial and continuing teacher education are a major obstacle in making inclusion come about. This paper presents a discussion of teacher education for inclusion and postulates two principles as the foundation for this education: the ethics of responsibility and being available to the other. Then, it presents the virtual learning object Incluir (LO Incluir), built with the objective of creating a tool to facilitate the preparation of teachers for education from the inclusion perspective. Divided into four modules (Limits, Diversity, Teaching and Deafness), this LO is intended to overcome the transmission of information, providing for reflection that promotes and mobilizes new practices within interactionist/constructivist assumptions. The reflections developed along the LO are reported and briefly discussed. A quantitative and qualitative analysis is in progress and will signal whether the LO reaches the objective for which it was created.

KEYWORDS: Special Education. Educational Inclusion .Teacher Education. Educational Technology.

\section{INTRODUÇÃo}

Mais do que estar preparado, no sentido de antecipado a alguma situação educativa particular, o que conta, o que vale à pena, é estar disponível, estar aberto à existência dos demais. (SKLIAR, 2008, p.11)

A inclusão social enquanto princípio de equiparação de oportunidades em uma sociedade democrática, na qual haveria respeito à diversidade, aceitação e reconhecimento

\footnotetext{
${ }^{1}$ Apoio: Fapergs; CNPq

${ }_{2}$ Curso de Psicologia/Centro de Ciências Humanas; Universidade de Caxias do Sul - UCS, Caxias do Sul, RS, Brasil. cabisol@ucs.br

${ }^{3}$ Pós-Graduação Mestrado em Educação/Centro de Filosofia e Educação, Universidade de Caxias do Sul - UCS, Caxias do Sul, RS, Brasil. cbvalent@ucs.br
} 
político das diferenças, vem introduzindo mudanças nas instituiçóes educativas desde a metade dos anos 1990 (MENDES, 2006). Porém, tanto o olhar do leigo quanto o olhar do especialista não tardam em identificar uma série de fatores que fazem do ideal da inclusão quase uma utopia, mesmo depois de duas décadas de debates e embates científicos, políticos e ideológicos. Entre estes fatores, geralmente são citadas as dificuldades das escolas de repensar os currículos e de construir recursos didático-pedagógicos apropriados aos diferentes modos de aprender e de estar na escola. Também costuma ser citada com insistência a escassez de recursos para mudanças estruturais fundamentais ao bem-estar dos estudantes e dos docentes, incluindo-se aqui uma ampla gama de reinvindicaçóes que se estende das adaptações do espaço físico à disponibilização de profissionais qualificados. (BISOL; STANGERLIN; VALENTINI, no prelo).

Essas dificuldades não se encontram apenas no cenário nacional. A partir de um extenso trabalho de revisão da literatura internacional referente às atitudes de professores quanto à inclusão, cobrindo um período que se estende de 1984 a 2000, Avramidis e Norwich (2002) concluíram que um sistema de apoio externo e equipes de apoio dentro da escola que possam trabalhar com os professores diante dos desafios colocados pelas necessidades educativas especiais têm uma consequência positiva direta nas práticas inclusivas. Além disso, os autores destacam a necessidade de oferecer oportunidades para formação de professores como uma dasgrandes prioridades para concretizar as políticas de inclusão. A hipótese é que se os professores são capacitados para dominar as competências necessárias para implementar uma inovação tal como esta (a inclusão), eles se tornam mais compromissados com a mudança.

$\mathrm{O}$ viés de análise que mais nos interessa nesse trabalho diz respeito, justamente, às lacunas na formação de professores como sendo uma das dificuldades mais significativas para a construção de práticas inclusivas. Ferreira (2007), por exemplo, afirma que a educação atual não oferece nem garante condiçóes satisfatórias para ser considerada efetivamente inclusiva e isto estaria associado à questão da falta de preparo do professor da classe regular para receber o aluno com necessidades educativas especiais. Portanto, uma questão central se coloca: que tipo de formação irá favorecer a inclusão?

O presente trabalho parte de uma discussão a respeito da formação de professores para a inclusão. Apresenta, em seguida, o objeto virtual de aprendizagem Incluir (OA Incluir), construído com o objetivo de criar um instrumento facilitador à formação de professores para a educação na perspectiva da inclusão.

\section{Desenvolvimento}

\subsection{A FORMAÇấo EM QUESTÁo}

Apesar de existir extensa literatura apontando para o fato de que informação não é suficiente para produzir mudança nas atitudes, crenças e valores, várias propostas de formação de professores ainda insistem em capacitar o professor para a educação inclusiva com base, principalmente, em transmissão de informação. $\mathrm{O}$ modelo centrado em palestras, muitas vezes esporádicas, ainda é comumente observado no Brasil quando se fala em formação continuada. Quanto à formação inicial, o modelo baseado em algumas poucas disciplinas ou aulas versando sobre as deficiências ainda pervade os cursos de licenciatura. $\mathrm{O}$ documento da Agência Européia (2009) para qualidade da educação inclusiva aponta que, para os professores 
trabalharem eficazmente em contextos inclusivos, é necessário o desenvolvimento de valores e atitudes apropriadas, além de competências, conhecimentos e compreensão da concepção de educação inclusiva. Destarte, considerando teorias e documentos, fica evidente que informaçóes são insuficientes para modificar práticas, pois os professores não são seres abstratos nem essencialmente intelectuais:

Essa concepção não dá conta da complexa dinâmica sociopsicológica envolvida nas relaçôes entre conhecimento, valores, atitudes e açóes. A cultura, os significados partilhados e o meio social permeiam as experiências individuais, construindo as referências com as quais ou em contraposição às quais as pessoas agem. O conhecimento é enraizado na vida social, expressando e estruturando a identidade e as condiçóes sociais dos que dele partilham (GATTI, 2003, p.195-196).

Nesse sentido, vale citar um estudo realizado por Gomes e Barbosa (2006) com 68 professores. A pesquisa teve como objetivo descrever as atitudes de docentes de salas regulares de ensino público fundamental perante a inclusão de um estudante portador de paralisia cerebral em sua turma. Entre as principais conclusóes deste trabalho, destaca-se: a) os professores que conhecem as características de uma pessoa portadora de paralisia cerebral têm atitudes mais positivas dos que os que desconhecem; b) participar de palestras não operou mudanças em suas atitudes; c) os que julgam ser de sua responsabilidade educar apresentam atitudes mais positivas. Os autores destacam que:

Todavia, os resultados evidenciam que não basta frequentar cursos, palestras, etc., como eles são atualmente. Há a necessidade de reformulá-los, para que possam se tornar impulsionadores para o desenvolvimento de atitudes positivas quanto à educaçáo inclusiva. Cabe ressaltar que a capacitação profissional só poderá apresentar resultados positivos, quando forem revistos e compreendidos, primeiramente, os posicionamentos e as atitudes dos professores frente à própria atuação profissional. Assim, se os docentes náo julgam ser de sua responsabilidade educar toda e qualquer pessoa, pouco útil é capacitá-lo com os mais avançados conhecimentos teóricos e práticos. (GOMES; BARBOSA, 2006, p.93)

As conclusóes a que chegam os autores desse estudo são muito precisas: conhecimento favorece atitudes positivas, porém deverá estar acompanhado de algo a mais, que é julgar ser de sua responsabilidade educar. Considerando a perspectiva da reflexão e envolvimento, também Santos e César (2010) analisam diversos estudos que destacam que os sentimentos, as atitudes e as preocupaçóes dos professores face à inclusão estão intimamente relacionados com o desenvolvimento de práticas e a construção de cenários mais inclusivos nas escolas de ensino regular.

Portanto, retornando à questão anterior sobre o tipo de formação para a inclusão, pode-se afirmar que esta deve ir além da informação e, de alguma forma, mobilizar o professor para sua responsabilidade como educador. Os questionamentos do sociólogo francês Eric Plaisance e do filósofo argentino Carlos Skliar são úteis para aprofundar essa discussão, tentando balizar uma possível direção para a proposta de ir "além da informação".

Plaisance (2010) pensa a questão da inclusão a partir de uma distinção entre a ética de convicção e a ética de responsabilidade, tal como proposta primeiramente por Max Weber. A ética da convicção diz respeito aos discursos generosos e complacentes sobre os princípios da inclusão, sem que se responda às situações concretas que ocorrem no dia a dia de crianças e 
professores. A ética da responsabilidade, por sua vez, indaga-se sobre as medidas concretas que podem favorecer um verdadeiro pertencimento.

É exatamente nessa perspectiva que podemos analisar a questão controversa da inclusão escolar de crianças com necessidades especiais. Como procuraremos mostrar mais adiante, é preciso superar o moralismo abstrato para encontrar uma ética concreta que permita abordar a questáo dos modos de acolhimento e de educação dessas crianças, identificando os obstáculos nas diferentes situaçôes. Portanto, a convicção deve ser articulada ao emprego de modalidades práticas da ação (PLAISANCE, 2010, p. 21)

Plaisance recorre a Emmanuel Levinas para destacar uma ética da responsabilidade que se exerce para com o outro, sem esperar que este retribua, numa abordagem concreta que salienta a relação face a face. E recorre também a Paul Ricoeur para enfatizar o termo "solicitude", no sentido de uma disposição favorável ao outro. Uma conclusão importante a que chega Plaisance é de que o motor fundamental da posição ética é recusar situaçóes inaceitáveis para a dignidade do ser humano, não em afirmações de convicção apenas, mas considerando as consequências.

Skliar (2008), por sua vez, situa sua posição através dos termos disponibilidade e responsabilidade. Para ele náo se trata de estar preparado para trabalhar com esta ou com aquela criança, por ser impossível estar preparado para aquilo que está por vir. Trata-se de estar disponível a receber e de ser responsável. O autor se pergunta por que, como docentes, não é possível ser responsável e estar disponível a alguém independente de seu corpo, de sua língua, de sua forma de aprender, de sua forma de estar no mundo. $\mathrm{O}$ autor propóe que a inclusão educativa deva estar relacionada a uma forma de hospitalidade, a um modo de receber o outro, uma acolhida. Isto requer uma mudança paradigmática: "uma transformação ética que desloque o olhar sobre os sujeitos apontados como diferentes, e que passe a ser um olhar colocado sobre nós mesmos, naquilo que se passa - pedagogicamente - entre nós" (SKLIAR, 2008, p. 15). Uma vez estabelecida a direção, resta a pergunta sobre o como: Como promover espaços de formação inicial ou continuada que possibilitem esse avanço? Como não se restringir à transmissão de informação e promover espaços de reflexão que mobilizem novas práticas?

\subsection{O OBJETO DE APRENDIZAGEM INCLUIR}

$\mathrm{O}$ objeto de aprendizagem Incluir (OA Incluir) foi construído objetivando criar um instrumento facilitador à formação de professores dentro dos princípios da ética da responsabilidade e da disponibilidade para o outro. Seu foco, portanto, não é a transmissão de informação, embora esta também se encontre presente em algum nível.

Enquanto instrumento facilitador entende-se que esse OA, de fácil acesso e disponível gratuitamente em www.objetoincluir.com.br, possa ser utilizado para o desenvolvimento de açôes de formação inicial de professores ou formação continuada, presenciais e/ou a distância.

O eixo de reflexão do OA Incluir é formado por quatro módulos: Limites, Diversidade, Docência e Surdez. Os dois primeiros módulos são amplos, no sentido de propor uma reflexão sobre a percepção de si e do outro e um convite para a superação das dicotomias normal/ anormal e deficiente/eficiente. $\mathrm{O}$ terceiro módulo se volta especificamente para o contexto 
escolar e o quarto, para a situação singular dos sujeitos surdos. Como descrito em detalhes em Bisol e Valentini (2012), cada módulo foi organizado em três níveis concebidos na tentativa de tornar efetivos os pressupostos construtivistas/interacionistas de aprendizagem: 1) mobilização; 2) provocação e 3) informação. Os recursos e materiais (vídeos, animaçóes, imagens e textos) foram criados especificamente para esse objeto.

Propóe-se mobilizar o usuário, em cada módulo, através de imagens, animaçóes ou vídeos que possam envolvê-lo e surpreendê-lo. Na sequência, os links levam para provocaçóes ou desestabilização das possíveis certezas sobre o tema, pretendendo deflagrar perturbações no sistema cognitivo, desencadeando a necessidade de construir novos saberes. Por fim, os textos articulam reflexôes que trazem consigo alguns pontos de suporte para um novo olhar com relação ao outro da inclusão.

Uma tarefa sempre muito difícil é a seleção dos focos, das abordagens, definir a linha que deverá conduzir as reflexóes para promover aberturas e questionamentos. As principais reflexóes propostas em cada um dos quatro módulos serão resumidas a seguir, demonstrando quais as escolhas conceituais feitas na construção deste objeto de aprendizagem.

\subsection{DEFICIÊNCIAS... EFICIÊNCIAS: QUAL O LIMITE DO OUTRO?}

O módulo intitulado Limites foi trabalhado a partir de apresentaçóes em vídeo da biografia de seis pessoas que alcançaram respeito, admiração e reconhecimento vencendo as barreiras que usualmente cercam a vida de pessoas com deficiências. São elas: Helen Keller, Emmanuelle Laborit, Aleijadinho, Pascal Duquenne, Evgen Bavcar e Stephen Hawking. Um sétimo vídeo apresenta as conquistas de atletas paraolímpicos. Os vídeos são acompanhados por um pequeno texto explicativo. No texto que acompanha esse módulo, o usuário/aprendente é chamado a refletir a respeito do olhar: um olhar que rapidamente é capturado por aquilo que marca a diferença em relação ao que se convencionou chamar de normal.

O lugar a partir do qual se lança o olhar para o outro diferente de si é questionado ao longo do texto, remetendo à ideia de que se olha a partir da relação que cada um estabelece com o corpo que habita, da relaçáo que se estabelece entre o próprio corpo e o que a sociedade considera normal, e da relação que se tem com os potenciais e as limitações do próprio corpo. Um olhar transversalizado, portanto, por um duplo movimento, de si ao outro, e do outra a si.

Uma pergunta essencial é: o que se entende por deficiência e por eficiência? Quem é deficiente? A deficiência é uma falha mensurável no corpo ou na mente de uma pessoa, ou é uma maneira de estar no mundo diferente na norma? Segundo Davis (1995), o corpo não é simplesmente algo físico. O corpo é um conjunto de atitudes. No entanto, nosso imaginário coletivo está ancorado nas capacidades e nas incapacidades, regido por aquilo que uma pessoa consegue ou não fazer. Este módulo é intitulado de "Limites" justamente buscando propor que se deixe falar este outro diferente de mim, para então aprender com ela ou ele sobre sua vida, seus potenciais e seus limites e não reproduzindo uma oposição reducionista e pré-estabelecida entre eficiência e deficiência, normalidade e anormalidade. 


\subsection{NORMAL, DESIGUAL, DIFERENTE: COMO SITUAR O OUTRO?}

No módulo intitulado Diversidade, o usuário é convidado a montar um retrato de família a partir de personagens que aparecem na tela. Desenhos de diferentes pessoas permitem a montagem de uma família padrão ou de uma família em que a diversidade se faz representar através de mais de grupo étnico, de pais ou filhos com deficiências ou de casais homoeróticos. Em seguida, o usuário é chamado a refletir brevemente sobre os termos normalidade, desigualdade e diferença a partir de provocaçóes que utilizam definiçóes de dicionário (palavras como anormal, desvio, padrão, média, norma, etc.), uma curva de distribuição normal na qual os personagens das famílias anteriores encontram ou não um lugar, e três breves recortes de ideias de autores que questionam esses conceitos. Essas provocaçóes complementam-se mutuamente e têm seu desfecho em um texto disponibilizado no objeto de aprendizagem que procura fazer uma reflexão integradora.

A reflexão propóe que se reconheça que, no âmbito dos discursos sociais, circula um anseio em relação à normalidade. Facilmente se pode reconhecer que esse anseio é alimentado pela mídia e pela ciência, principalmente pelas áreas da Medicina e da Psicologia: os índices normais, os comportamentos normais. Retoma-se, nessa linha argumentativa, a contribuição da estatística no estabelecimento da noção de normal como imperativo da sociedade moderna. Adolphe Quetelet (1796-1847) formulou o conceito de homem médio ou homem padrão: este ser humano abstrato seria a média de todos os atributos humanos em um dado país (DAVIS, 1995). O estabelecimento da média determina simultaneamente o espaço do desvio e contribui para a constituiçãao de zonas de pertencimento e de exclusão. A distância da norma, padrão ou média muito frequentemente vem acompanhada de desvalorização e discriminação.

Porém, sabemos que ninguém consegue responder exatamente aos padróes: os corpos fogem da média em algum aspecto, o comportamento desliza por entre as rachaduras das convenções. É nas diferenças que construímos nossa singularidade, que nos distinguimos uns dos outros. Embora atualmente se reconheça o direito à diferença, isso se dá através de um esforço discursivo que aparece na forma de leis, cotas, eventos, ações afirmativas, propagandas. $\mathrm{O}$ esforço denuncia a dificuldade de se construir espaços para as diferenças nas instituiçóes (estado, escola, família, trabalho, etc.). Como construir um espaço legítimo de pertencimento para o outro que não esteja calcado nas ideias em torno da noção de normalidade?

\subsection{A DIVERSIDADE NA SALA DE AULA: QUAIS OS DESAFIOS PARA O DOCENTE?}

O módulo intitulado Docência apresenta, em sua tela inicial, uma sala de aula. No quadro leem-se as palavras que constituem links: as diferenças, as adaptaçóes, os paradigmas, as relaçóes.

Ao clicar no link das diferenças, o usuário depara-se com uma animação de uma charge na qual um professor pede aos alunos que tomem os seus lugares. Trata-se de figuras geométricas: só encontrarão lugares aqueles que tiverem o mesmo formato do professor (charge baseada em HARPER et al., 2003). O objetivo dessa provocação é pensar em como encontrar espaço para as diferenças em uma instituição que nasceu e é marcada pela disciplina, pela uniformidade. A escola, da maneira como nós a conhecemos, tem uma estrutura linear e hierárquica muito visível. Uma forma racional de organizar o espaço e o tempo de aprender, 
com os saberes separados em disciplinas e organizados em séries, em ordem crescente de complexidade. Uma racionalidade herdeira da organização social que impera há mais ou menos três séculos (FOUCAULT, 1987).

É importante para o professore perceber que, das séries iniciais ao ensino superior, o espaço onde se concretiza o ensinar e o aprender é organizado a partir de uma lógica afeita à homogeneização. Diante disso, não é de se estranhar que no imaginário do professor, ele mesmo fruto e herdeiro dessa lógica, tudo que se aproxime desta forma de organização seja considerado mais adequado, mais correto, mais desejável. É fácil compreender que o professor ainda se prenda a uma ideia de aluno que deve se adaptar à estrutura, às exigências e à rotina da escola.

Os professores são os primeiros a identificar que, observando a escola em seu cotidiano, cada vez mais vemos que esta não é a regra, e sim a exceção. Ao desejo de organização sobrepóe-se uma realidade cada vez mais complexa, onde as formas de viver e de se constituir enquanto família, homem, mulher, trabalhador, ganham contornos cada vez mais fluidos, menos institucionalizados, uma subjetividade midiática em que a opinião pessoal e a imagem substituem a norma (COREA; LEWKOWICZ, 2004). É essencial pensar que são novos tempos para velhas instituições: do ideal de uniformidade à necessidade de flexibilizar e ressignificar os espaços, as relaçóes, as práticas.

Ao clicar no link dos paradigmas, o usuário é convidado a situar as mudanças históricas que culminaram, justamente, no desencadeamento das atuais políticas de inclusão. Uma linha do tempo, complementada pelo texto disponibilizado no objeto de aprendizagem, permite situar quatro grandes momentos históricos. Os quatro grandes momentos históricos identificados nessa reflexão são: exclusão, institucionalização, integração e inclusão.

A exclusão total do convívio social é a marca da Antiguidade e da Idade Média, amenizada aos poucos pelo moralismo cristáo. Um novo modo de conceber a relação entre o corpo sadio e o corpo doente surge a partir do século XVII, quando a deficiência passa a ser vista como doença de natureza orgânica. Nesse período surgem as primeiras práticas sociais de atenção ao deficiente com a criação de instituiçóes para cuidado, proteção, e tratamento médico. Enquanto o período anterior é caracterizado pela lógica da exclusão, neste período que seguiu até meados do século XX a lógica preponderante é a da institucionalização (TEZANI, 2005). A necessidade da criação de serviços de reabilitação para atender aos soldados que retornavam das Grandes Guerras do século XX, o processo geral de reflexão sobre os direitos humanos, os altos custos de manutenção das grandes instituições, entre outras características do século XX, deram início à reformulação de ideias e à busca de novas práticas no trato com a pessoa com deficiência.

Vê-se surgir uma lógica que é caracterizada pela oferta de serviços. Esta lógica tem a vantagem de tentar proporcionar a adaptação ou readaptaçáo à sociedade, porém está pautada na ideia de normalização: cabe à pessoa com deficiência chegar o mais perto possível do funcionamento normal. O conceito-chave deste período é o de integração - adequar o sujeito à sociedade. Ainda vigente, esta lógica começou a sofrer mudanças por volta dos anos 90, tendo como marcos a Declaração Mundial de Educação para Todos (BRASIL, 1990), a Declaração de Salamanca (BRASIL, 1994), a Convenção de Guatemala de 1999, promulgada no Brasil 
pelo Decreto no 3.956/2001 (BRASIL, 2001) e a Convenção sobre os Direitos das Pessoas com Deficiências (ONU, 2006).

A mudança para uma lógica de suporte ou inclusão está se dando paulatinamente, a partir da compreensão de que a sociedade deve se desenvolver e se modificar para acolher a pessoa com deficiência e qualquer pessoa que se encontre excluída por algum motivo, seja ele de ordem étnica, religiosa, econômica, cultural. A convivência não segregada deve ser oportunizada através do cuidado com a acessibilidade e a oferta de recursos que possibilitem o desenvolvimento de competências e habilidades.

Esse percurso no tempo ilustra como a educação atende e reflete a sociedade que a constitui e que é por ela constituída, reproduzindo os saberes que compóem uma cultura. Cada época produziu diferentes modos de educar, cada época teve a sua noção de quem são os todos para os quais a vida em sociedade (e o direito à educação, portanto) seria acessível. A educação, para ser inclusiva, deve se basear no reconhecimento das diferenças, na busca de valores e práticas comuns, na convivência com a diversidade. Justamente, o que coloca ao docente a necessidade de produzir novas formas de conduzir sua prática e o cotidiano em sua sala de aula.

Tais questóes são problematizadas a partir do link das adaptações. O usuário é convidado a refletir sobre as formas de ensinar a partir da provocação gerada por uma charge em que um professor é representado com uma boca imensa, enquanto os alunos sentados são representados por grandes orelhas (HARPER et al., 2003).

O texto disponibilizado no objeto de aprendizagem convida a refletir sobre a tendência de se estabelecer um certo ideal do que seja o ensinar e do lugar que deve ocupar o aluno nesse processo. Como o professor se sente quando chamado a responder ao aluno que não se encaixa nesse ideal? Diante do inesperado que se apresenta na forma de um aluno estrangeiro, de um aluno surdo, ou de um deficiente visual, ou de qualquer diferença que marque que há algo desconhecido, que foge ao usual?

A alternativa de negar a diferença, anulando o outro, encontra cada vez menos espaço na sociedade contemporânea que procura conceder à diversidade um lugar. A "pedagogia do outro que deve ser anulado" (palavras de SKLIAR, 2003) está na contramão de todo discurso e esforço para a inclusão que temos visto em nosso país nas últimas duas décadas, mesmo que isso ocorra de uma forma ingênua ou falha. Quando cai o ideal ou a ilusão da mesmice, criase a tensão: o que fazer neste espaço de ensinar se os caminhos já conhecidos não oferecem respostas seguras? Novidade. Convite a pensar. Gallo (2008, p. 15) diz que "educar significa lançar convites aos outros; mas o que cada um fará - e se fará - com estes convites, foge ao controle daquele que educa”. Brincando com estas palavras, podemos pensar que educar reconhecendo a diferença é lançar convites a si mesmo para quebrar a mesmice do seu fazer, para permitir que novos lugares possam existir para o outro e para si neste fazer.

Nessa lógica se fazem necessárias mudanças didático-pedagógicas. "Adaptaçôes" talvez seja pensar pequeno, talvez um pensar ainda titubeante, que não conseguiu conquistar plenamente um espaço para a alteridade. Talvez seja ainda vago. Mas quem sabe, um pensar que vá em direção à provocação de Skliar (2003, p. 47), um pensar que possa propor (a si e ao 
outro): "não está mal ser o que és", mas também: "não está mal ser outras coisas além do que já és”. Este sim um espaço aberto para a reinvenção. Na prática, que reinvenções seriam estas? Impossível nomeá-las, porque invenção exige autoria. Caberá a cada um escutar a si e aos seus alunos para poder reinventar.

\subsection{SURDO OU DEFICIENTE AUDITIVO?}

A tela de abertura do módulo intitulado Surdez apresenta seis imagens em movimento, cada uma delas constituindo um link que dá acesso a uma provocação e um texto referindo algum aspecto importante de ser conhecido quando se está em contato com pessoas surdas ou deficientes auditivos. São eles: cultura surda, Língua de Sinais, diferenças entre surdez e deficiência auditiva, alfabeto datilológico, a escrita para o surdo e o intérprete para língua de sinais.

A primeira imagem retrata uma apresentação de teatro em que o artista é surdo. A seguir, ao usuário se apresentam cartazes, fotos, capas de livros que remetem a produçóes culturais sobre surdos, de surdos, para surdos e situaçóes culturais promovidas e compartilhadas pela comunidade surda. Chama-se atenção, dessa maneira, para o fato de existir uma cultura surda compartilhada por sujeitos surdos. Uma cultura minoritária, como tantas outras, que sustenta espaços específicos para os membros de sua comunidade e quem de perto convive. Ao mesmo tempo, uma cultura que mantém pontos de tensão, de contraposição ao olhar dos ouvintes. Referências culturais permitem que os surdos se considerem sujeitos culturais e não deficientes (PERLIN, 2007).

A segunda imagem remete à escrita do surdo. A leitura e a escrita são, juntamente com a matemática, as habilidades em torno das quais se colocam as maiores expectativas e tensóes no ambiente escolar. Para o sujeito surdo essa questão apresenta nuances específicas, ligadas ao fato de que a língua de sinais é a língua natural para a pessoa surda. Sendo assim, a língua de sinais funciona como suporte do pensamento e meio de comunicação para o surdo, porém não é esta a língua na qual se deve operar a leitura e a escrita.

A terceira imagem chama a atenção para a profissão do intérprete de língua de sinais. A profissão de Tradutor e Intérprete de Libras foi regulamentada em 2010 através da Lei no 12.319 (BRASIL, 2010). O intérprete de língua de sinais é um profissional ouvinte que tem competência e fluência em língua de sinais para viabilizar a comunicação entre surdos e ouvintes, ou seja, entre a língua de sinais utilizada em uma determinada comunidade surda e a língua oral falada pela comunidade majoritária ouvinte. $\mathrm{O}$ intérprete de língua de sinais media a interlocução que se estabelece entre duas línguas distintas: de forma verbal (língua de sinais para língua oral) ou de forma gestual (língua oral para língua de sinais). Desta maneira, o ato interpretativo ocorre sempre na presença física do intérprete, que utiliza para isso a voz ou o gesto.

A quarta imagem faz referência ao uso do aparelho auditivo, ou prótese auditiva. De um ponto de vista puramente orgânico, surdez e deficiência auditiva são termos sinônimos utilizados para referir qualquer tipo de perda auditiva em grau leve, moderado, severo ou profundo, em um ou ambos os ouvidos. Porém, uma compreensão da surdez baseada em uma perspectiva histórica e cultural enfatiza diferentes modos de vivenciar as diferenças de audição. Os surdos, ou Surdos com letra maiúscula, como proposto por alguns autores, são pessoas que 
não se consideram deficientes, utilizam uma língua de sinais, valorizam sua história, arte e literatura e propóem uma pedagogia própria para a educação das crianças surdas. Os deficientes auditivos seriam as pessoas que não se identificam com a cultura e a comunidade surda.

As duas últimas imagens são destinadas a uma reflexão sobre o alfabeto datilológico e a língua de sinais. $\mathrm{O}$ alfabeto datilológico é apresentado para fins de diferenciação da língua de sinais, uma vez que um erro comum às pessoas não familiarizadas com a questão da surdez é pensar que as línguas de sinais são uma soletração de palavras oriundas das línguas orais. $\mathrm{O}$ linguista norte-americano William C. Stokoe (STOKOE, 1960/2005) demonstrou, nos anos 60, que as línguas de sinais são uma verdadeira língua, com estrutura semelhante às línguas orais. Antes de suas pesquisas pioneiras, as línguas de sinais eram consideradas uma coleção de gestos, uma pantomima. No Brasil, a Lei no 10.436 de 24 de abril de 2002 (BRASIL, 2002) reconheceu a Língua Brasileira de Sinais como meio legal de comunicação e expressão, determinou o apoio ao uso e difusão da língua e sua inclusão obrigatória nos cursos de formação de professores nos níveis médio e superior e nos cursos de Fonoaudiologia.

Compreender as especificidades da surdez, da cultura surda, da língua de sinais e de como se dá a aquisição da escrita pela pessoa surda é fundamental para que o educador intervir adequadamente no processo de ensino e aprendizagem.

\section{Conclusóes}

Pensar a respeito dos princípios que podem nortear a formação de professores para a inclusão exige um percurso entre teoria e prática. As escolhas feitas para a organização do objeto de aprendizagem Incluir procuraram circunscrever reflexóes que permitissem pensar em termos de uma ética da responsabilidade e de uma disponibilidade para o outro. De um universo amplo de questóes que poderiam ter sido abordadas, escolheram-se algumas que, acredita-se, podem auxiliar a nomear e estabelecer alguns parâmetros conceituais. $\mathrm{O}$ intuito, retomando as questóes inicialmente apontadas neste artigo, foi conceber uma proposta de formação que, deslocando seu foco para além da transmissão de informação, promova e mobilize uma atitude reflexiva e crítica sobre o processo de ensino e aprendizagem e contribua para a construção novas práticas.

A estrutura do OA Incluir foi pensada para conduzir a movimentos de mobilização e provocação, trazendo informaçóes em um plano secundário. Para que isso se efetivasse foi necessário percorrer um caminho técnico, em termos de decisóes quanto à estrutura do objeto, sua arquitetura interna e a composição de cada módulo. Também foi necessário realizar eleições teóricas, definindo que reflexóes propor e a partir de que conceitos. As decisóes foram tomadas sempre no sentido de tentar promover aberturas, questionamentos, cuidando para que uma linguagem acessível e convidativa não comprometesse o rigor conceitual.

O OA Incluir vem sendo utilizado em oficinas presenciais com professores de diversos níveis de ensino e em atividades presenciais ou a distância com acadêmicos das licenciaturas, psicologia, especialização em psicopedagogia e áreas afins. Uma análise quantitativa e qualitativa do objeto está em andamento, sendo realizada a partir de um livro de visitas disponibilizado no próprio objeto. Neste, os usuários encontram um questionário anônimo, instrumento composto por 20 questóes fechadas e seis abertas. As questões fechadas versam sobre o uso (se é 
fácil de usar, de navegar, se é atraente e engajador), do conteúdo (adequação, relevância, clareza e concisão) e como recurso de ensino e aprendizagem (se informa, se promove ressignificação, se promove reflexão). Quatro questóes abertas permitem ao usuário expressar opiniōes sobre os vídeos, imagens, textos e animações. As duas últimas questóes abertas os participantes foram convidados a se houve alguma mudança em seu modo de conceber a inclusão e se algo mudou na sua maneira de conceber a diversidade, a diferença ou as necessidades especiais.

A estrutura aberta do objeto permitirá também agregar novos módulos, conforme se verifique a aplicabilidade e relevância deste recurso. Um exemplo seria conceber módulos específicos para outras deficiências sensoriais além da surdez. Também seria possível pensar em outro contexto onde os desafios da inclusấo tem chamado a atenção da sociedade, como é o caso do mercado de trabalho. Enfim, trata-se de expandir os recursos e trabalhar para construir novas geraçôes de professores e profissionais para quem a ética não seja uma questáo retórica e para quem a disponibilidade ao outro esteja em primeiro lugar.

\section{REFERÊNCIAS}

AGÊNCIA européia para o desenvolvimento da educação especial. Princípios-Chave para a Promoção da Qualidade na Educação Inclusiva - Recomendaçôes para Decisores Políticos, Odense, Denmark: European Agency for Development in Special Needs Education, 2009.

AVRAMIDIS, E.; NORWICH, B. Teachers' attitudes towards integration/inclusion: a review of the literature. European Journal of Special Needs Education, v. 17, n. 2, p. 129-147, 2002.

BISOL, C. A.; VALENTINI, C. B. Desafios da inclusão: uma proposta para a qualificação de docentes no Ensino Superior via tecnologias digitais. Revista Portuguesa de Educą̧ão, v. 25, n. 2, p. 263-280, 2012.

BISOL, C. A.; STANGHERLIN, R.G.; VALENTINI, C. B. Educação inclusiva: estudo de estado da arte das publicaçôes científicas brasileiras em Educação e Psicologia. Cadernos de Educação (UFPel), n. 44. No prelo.

BRASIL. Declaração Mundial sobre Educação para Todos: plano de ação para satisfazer as necessidades básicas de aprendizagem. UNESCO, Jomtiem/Tailândia, 1990.

. Declaração de Salamanca e linha de ação sobre necessidades educativas

especiais. Brasília: CORDE, 1994.

. Decreto No 3.956, de 8 de outubro de 2001. Promulga a Convençáo Interamericana para a Eliminação de Todas as Formas de Discriminação contra as Pessoas Portadoras de Deficiência. Guatemala: 2001.

. Ministério da Educação. Secretaria de Educação Especial. Lei No. 10.436, de 24 de abril de 2002. Dispóe sobre a Língua Brasileira de Sinais - LIBRAS e dá outras providências. Brasília/DF, 2002.

. Ministério da Casa Civil. Lei No 12.319, de 1 de setembro de 2010. Regulamenta a profissão de Tradutor e Intérprete da Língua Brasileira de Sinais - LIBRAS. Brasília/DF, 2010.

COREA, C.; LEWKOWICZ, I. Pedagogía del aburrido. Escuelas destituidas, familias perplejas. Buenos Aires, Argentina: Paidós, 2004. 214p

DAVIS, L. J. Enforcing normalcy: Disability, deafness, and the body. London: Verso, 1995. 
FERREIRA, M. E. C. O enigma da inclusão: das intençôes às práticas pedagógicas. Educação e Pesquisa, v. 33, n. 3, p. 543-560, dez. 2007.

FOUCAULT, M. Vigiar e Punir: nascimento da prisão. Tradução de Raquel Ramalhete. Petrópolis, Vozes, 1987. 288p.

GALLO, S. Eu, o outro e tantos outros: educação, alteridade e filosofia da diferença. In:

CONGRESSO INTERNACIONAL COTIDIANO, Diálogos sobre Diálogos, 2., Rio de Janeiro, 2008. Anais..., Rio de Janeiro: Unviversidade Federal Fluminense, 2008.

GATTI, B. A. Formação continuada de professores: a questão psicossocial. Cadernos de Pesquisa, n. 119, p. 191-204, ago. 2003.

GOMES, C.; BARBOSA, A. J. G. Inclusão escolar do portador de paralisia cerebral: atitudes de professores do ensino fundamental. Revista Brasileira de Educação Especial, v. 12, n. 1, p. 85-100, abr. 2006.

HARPER, B. et al. Cuidado escola!. Editora Brasiliense. São Paulo, 36. ed. 2003.

MENDES, E. G. A radicalização do debate sobre inclusão escolar no Brasil. Revista Brasileira de Educação, Rio de Janeiro, v.11, n.33, p.387-405, 2006.

ORGANIZAÇÃO DAS NAÇÕES UNIDAS. Convenção sobre os Direitos as Pessoas com Deficiência, 2006.

PERLIN, G. Prefácio. In: QUADROS, R. M.; PERLIN, G. (Org.). Estudos Surdos II. Petrópolis, RJ: Arara Azul, 2007. p. 9-17.

PLAISANCE, E. Ética e inclusão. Cadernos de Pesquisa, São Paulos, v. 40, n. 139, p.13-43, 2010.

SANTOS, J.; CÉSAR, M. Atitudes e preocupaçôes de professores e outros agentes educativos face à inclusão. Interacçôes, v.6, n.14, p.156-184, 2010.

SKLIAR, C. B. A educação e a pergunta pelos Outros: diferença, alteridade, diversidade e os outros “outros". Ponto de Vista: revista de educação e processos inclusivos, n. 5, p. 37-49, 2003. - ¿Incluir las diferencias? Sobre un problema mal planteado y una realidad insoportable.

Orientación y sociedad, v. 8, p. 1-17, dez. 2008.

STOKOE, W. C. Sign Language Structure: An Outline of the Visual Communication Systems of the American Deaf. Journal of Deaf Studies and Deaf Education, v. 10, n. 1, p. 3-37, 1960/2005.

TEZANI, T.C.R. Consideraçóes sobre a história da educação especial no Brasil: movimentos e documentos. Revista da FAEEBA - Educação e Contemporaneidade. Salvador, v. 14, n. 24, p. 205-216, 2005.

Recebido em: 30/09/2013

Reformulado em: 14/05/2014

Aprovado em: 15/05/2014 